\title{
Análise Dialógica de uma Formação Continuada na Modalidade a Distância: compartilhando um percurso teórico-metodológico
}

\section{Dialogical analysis of a continuous education in the distance modality: sharing a theoretical-methodological trajectory}

\begin{abstract}
Resumo:
Este artigo busca compartilhar um percurso teórico-metodológico criado a partir da análise dialógica de uma experiência de formação continuada para professores/as, na modalidade a distância. Tal percurso encontrou um ponto de conexão entre as teorizações do Círculo de Bakhtin sobre as relações dialógicas e sobre o enunciado concreto, com a noção de dispositivo em Michel Foucault. A leitura e a escrita foram as principais ferramentas metodológicas. Quando se parte da dialogia como perspectiva de trabalho, não há uma imagem de método a ser reproduzida, mas um percurso a ser criado. A partir de nossa pesquisa compartilhamos algumas pistas que poderão auxiliar investigações dialógicas em espaço virtual.
\end{abstract}

Palavras-chave: Análise dialógica. Formação continuada. Educação a Distância. Ambiente virtual.

\section{Abstract:}

This article aims sharing a theoretical-methodological trajectory created through a dialogical analysis of the experience of a continuous education in the distance modality for teachers. This path has found a connection point between Bakhtin Circle theorization about the dialogical relations and concrete utterances with the notion of dispositive in Michel Foucault. The reading and writing were the mainly methodological tools. When using a dialogical approach as a work perspective, there is no image of method to be reproduced, but a trajectory to be created. Through our research we share some tracks that can assist of dialogical investigations in the virtual space.

Keywords: Dialogical analysis. Continuous education. Distance education. Virtual environment.

GROFF, Apoliana Regina; MAHEIRIE, Kátia. Análise Dialógica de uma Formação Continuada na Modalidade a Distância: compartilhando um percurso teórico-metodológico. Informática na Educação: teoria e prática, Porto Alegre, v. 18, n. 2, p. 163-176, jul./dez. 2015.

\author{
Apoliana Regina Groff
}

Kátia Maheirie

\section{Introdução}

E ste artigo deseja compartilhar um percurso teórico-metodológico, construído em uma pesquisa mais ampla na área da psicologia que, desde uma perspectiva dialógica (BAKHTIN, 2010, 2011), analisou como a violência foi enunciada em um curso de especialização ofertado na modalidade a distância, para professores e professoras de escolas públicas dos três estados do sul do Brasil, entre 2010 e 2011. O referido curso teve como principal objetivo instrumentalizar estes/as profissionais para a construção de projetos de intervenção educacionais que pudessem contribuir na prevenção e no enfretamento de violências que afetam crianças e adolescentes em contextos educativos.

Como um curso desenvolvido na modalidade a distância, este possuía um ambiente 
virtual onde aconteciam praticamente todos os processos de ensino, trocas entre professores, tutores, monitores e cursistas em fóruns de discussão e em outras modalidades de comunicação, e onde os cursistas realizavam a postagem dos trabalhos escritos desenvolvidos durante a formação. O ambiente virtual reunia também os principais materiais didáticos, além de imagens, textos e vídeos complementares ao seu conteúdo principal. Tendo em vista que este curso aconteceu durante um período de aproximadamente 15 meses, iniciando com 528 cursistas e finalizando com 328 , com uma equipe média de 20 tutores, 18 monitores e sete professores (GROFF, 2011), pode-se compreender a densidade de discursos produzidos no ambiente virtual.

O objetivo geral de nossa pesquisa era analisar como a violência havia sido enunciada na experiência do curso, considerando os materiais didáticos e os discursos produzidos pelos cursistas na trajetória da formação (GROFF, 2015). Assim, num primeiro momento, nossos desafios foram delimitar o plano da investigação e criar um percurso metodológico que abarcasse os limites temporais da pesquisa, bem como a complexidade da dialogia como uma perspectiva de trabalho no plano de uma investigação em ciências humanas.

No início deste percurso, buscamos, então, nos aproximar de outros estudos e investigações que tinham como um de seus aspectos a análise de ambientes virtuais e/ou a formação continuada de professores na modalidade a distância. Realizamos um breve mapeamento da produção acadêmica sobre educação a distância (EaD) e ambientes virtuais, a partir do levantamento de pesquisas de doutorado defendidas entre 2000 e 2011, publicadas no Banco de Teses da Coordenação de Aperfeiçoamento de Pessoal de Nível Superior (CAPES), com foco na Área das Ciências Humanas ${ }^{1}$, buscando reconhecer, principalmente, as perspectivas metodológicas em relatos de pesquisas, com os quais poderíamos de algum modo conectá-los a nossa investigação.

Entendemos o mapeamento da produção acadêmica sobre um determinado assunto como um importante procedimento no processo da pesquisa, pois, ao mesmo tempo que nos permite olhar para um apanhado de estudos e com eles estabelecer diálogos, este mapa possibilita localizar e desnaturalizar nossa investigação, realizar distanciamentos, rever objetivos e redesenhar nossos projetos de pesquisa. No mapeamento que realizamos, não encontramos necessariamente estratégias metodológicas que pudessem ser diretamente utilizadas em nosso trabalho de pesquisa. Contudo, sublinhamos alguns elementos que se destacaram nos estudos encontrados e certa predominância de metodologias quantitativas com a utilização de programas para coleta de dados e de softwares para a análise.

Este levantamento nos possibilitou também um olhar amplo sobre o modo como os pesquisadores vêm produzindo conhecimentos a partir da análise de ambientes virtuais e de cursos na modalidade a distância e, sobretudo, clarificou a necessidade que tínhamos em criar um percurso de pesquisa singular, considerando o nosso objeto de estudo e a análise dialógica que pretendíamos realizar.

\footnotetext{
1 Segundo a tabela de Áreas de Conhecimento da CAPES, a Área Ciências Humanas engloba: Ciência Política, Educação, Psicologia, Geografia, História, Arqueologia, Antropologia, Sociologia, Teologia, Filosofia. Dentro desta Área acrescentamos também as teses que encontramos vinculadas ao Programa de Pós-Graduação em Informática na Educação da Universidade Federal do Rio Grande do Sul (UFRGS).
} 


\section{Formação de Professores, Edu- cação a Distância e Ambientes Vir- tuais}

A formação continuada de professores e professoras na modalidade a distância tem se intensificado na última década, em especial, após sua regulamentação pelo Decreto no 5.622/2005 que dispõe sobre a educação a distância como modalidade educacional. Por meio da utilização de ambientes virtuais, estas formações tem produzido uma quantidade gigantesca de informações quantitativas e qualitativas. Há, neste sentido, uma grande produção de materiais escritos e imagéticos, um volume expressivo de dados quantitativos sobre os docentes e estudantes, sobre o acesso destes aos materiais disponibilizados pelos cursos e que sinalizam, entre outros aspectos, a evasão, o mau desempenho dos cursistas e a interação entre professor e aluno (REATEGUI et al., 2011). Nesta direção é crescente na última década a produção acadêmica em torno destas questões, bem como de periódicos específicos sobre Educação a Distância².

No levantamento das teses disponíveis no Banco da CAPES, entre os anos 2000 e 2011, com o descritor formação de professores e educação a distância, observamos que nos últimos cinco anos houve um aumento na produção de pesquisas de doutorado em torno desses assuntos, sendo que dos 128 trabalhos encontrados, 86 destes se concentram entre os anos de 2007 e 2011. Há também uma prevalência na Área de Ciências Humanas

\footnotetext{
${ }^{2}$ Encontramos no Portal de Periódicos da CAPES dois periódicos internacionais e um nacional com foco na Educação a Distância: a Revista Iberoamericana de Educación a Distância (RIED) e a Revista de Educación a Distância (RED), ambas com sede na Espanha; e a Revista Brasileira de Aprendizagem Aberta e a Distância (RBAAD).
}

com 101 das teses mapeadas e, em especial, na subárea da educação, onde se vinculavam 89 destas teses. Já no Programa Informática na Educação vinculam-se seis trabalhos, em Programas de Pós-Graduação em Psicologia três, em um Programa de Pós-Graduação em Educação Científica e Tecnológica duas teses, e uma tese numa Pós-Graduação em Políticas Públicas e Formação Humana.

Com a leitura dos resumos destes trabaIhos, identificamos que diversos estudos destacavam a crescente oferta de cursos de formação inicial ou continuada para professores na modalidade a distância e os desafios de políticas públicas adequadas a formação de professores em exercício. Dentre o foco das pesquisas estão, sobretudo, estudos de caso que buscam analisar os processos de interação entre professor-aluno no contexto da educação a distância; estudos sobre inovações pedagógicas e tecnológicas em cursos na modalidade a distância; investigações sobre a formação dos professores e sobre a formação e o papel dos tutores na EaD; avaliação de processos de aprendizagem; concepções de ensino e aprendizagem; estudos sobre políticas de formação continuada; sobre a mercantilização da EaD.

Quanto aos estudos envolvendo o descritor ambientes virtuais de ensino e aprendizagem, encontramos 94 teses entre os anos de 2000 e 2011. Destas, 48 são da Área de Humanas, predominando 29 trabalhos vinculados a Programas de Pós-Graduação em Educação e 15 no Programa Informática na Educação. Prevalecem estudos que tem como interesse investigar o potencial do ambiente virtual nos processos de aprendizagem; estudos que se debruçam sobre a mediação pedagógica no ambiente virtual a partir de ferramentas específicas como fóruns e chat's; outros avaliam o ambiente virtual a partir do Projeto Político Pe- 
dagógico do curso; há estudos sobre a constituição de comunidades virtuais e os processos de interação no ambiente virtual como forma de potencializar a aprendizagem dos alunos; pesquisas que analisam a formação dos docentes; e algumas teses que estudam a possibilidade de autoria coletiva em ferramentas do ambiente virtual que possibilitam a escrita de textos em grupo.

Com relação às metodologias utilizadas pelas pesquisas deste levantamento, identificamos trabalhos que desenvolveram estudos de caso, pesquisa-intervenção, etnografia virtual, pesquisa documental e, ainda, trabalhos de cunho quantitativo-utilizando recursos oferecidos pela plataforma moodle e outros programas específicos para análise de dados. A leitura dos resumos destas teses apontou questões importantes para a criação do nosso percurso metodológico, em especial, para a especificidade de nossa pesquisa, já que não encontramos outro trabalho que tivesse como objetivo analisar, desde uma perspectiva dialógica, a produção discursiva em torno do conteúdo teórico de uma formação na modalidade a distância. Por conta disso, também não encontramos estratégias metodológicas que indicassem um modo de entrelaçar a análise deste conteúdo considerando tanto os materiais didáticos ofertados, quanto os enunciados dos estudantes. Por fim, a pesquisa em base de dados sinalizou a necessidade que tínhamos em criar um percurso metodológico para nossa pesquisa.

\section{Um Percurso Teórico-Metodológi- co}

A inspiração para a construção metodológica de nossa pesquisa encontrou um ponto de conexão entre as teorizações do Círculo de
Bakhtin sobre as relações dialógicas e sobre o enunciado concreto, com a noção de dispositivo em Michel Foucault (1979, 2009, 2012). A partir destes autores localizamos o curso de especialização em um dispositivo de formação de professores, aglutinador de discursos, instituições, tecnologias, tempos, espaços, corpos, regulamentos, leis e práticas em que atuam formas de exercício de poder ancorados em instrumentos de saber, sendo o dispositivo "[...] a rede que se pode estabelecer entre estes elementos" (FOUCAULT, 1979, p. 244).

Neste contexto, situamos o curso em um dispositivo que obedece a lógica contemporânea das formações continuadas emergentes nas sociedades de controle que põem em funcionamento visibilidades e dizibilidades em um determinado momento histórico (DELEUZE, 2010), respondendo a uma urgência no campo da educação, a saber, a formação de professores para a prevenção e o enfretamento das violências nas escolas. Um dispositivo "[...] pelo qual os sujeitos se constituem como elemento e como resultado no conjunto das práticas sociais" (SKLIAR; TÉLLEZ, 2008, p. 29).

Assim, em um dispositivo de formação de professores, o curso de especialização "[...] torna-se um lugar, instituído sob a forma de mecanismos e estratégias de ação, onde se conectam formas de saber, tecnologias de poder e modos de constituição do eu" (SANTOS, 2006 , p. 26). Um lugar em que se atualizam determinadas relações dialógicas em forma de enunciados concretos, produzindo uma rede discursiva - entre instituições, leis, normas, práticas e enunciados - com a qual nos relacionamos e atuamos na produção de realidades.

A perspectiva que adotamos em nossa pesquisa, recortou este dispositivo a partir do interesse em estudar como a violência foi enunciada na experiência de uma formação continuada para professores e as relações dia- 
lógicas que caracterizam tais enunciados. Nossos objetivos específicos eram: dar visibilidade e audibilidade às múltiplas vozes e ideias-força presentes nos enunciados de violência, tanto dos cursistas como dos materiais do curso; demarcar os lugares de enunciação da violência; como o outro foi enunciado nos discursos sobre as violências que acontecem nas escolas; quais linguagens foram utilizadas na produção destes discursos e; olhar para as mudanças e permanências nos enunciados de violência no processo da formação dos cursistas.

Uma análise dialógica, no entanto, não se limita à dimensão linguística do enunciado, pois a enunciação está envolvida em condições históricas, políticas e sociais, ou seja, a uma multiplanaridade de onde o discurso emerge em meio a relações de poder. Cabe dizer, também, que um enunciado não reflete este contexto multiplanar, o qual Bakhtin e Volochínov (1976) também chamam de extraverbal, como um espelho, pois o extraverbal não é a causa de um enunciado, ele se integra a ele desde dentro e de forma constitutiva, sendo atualizado no próprio ato de enunciação. Assim, a linguagem só ganha vida e se efetua na rede de comunicação entre as pessoas, seja por meio de atos de fala, seja pelo discurso escrito, imagético, gestual, sonoro.

Um enunciado expressa a condição múltipla e complexa que o envolve, e a abertura que ele engendra quando de sua criação e efetuação na rede de comunicação cotidiana. Portanto, o que denominamos de enunciado pode se expressar a partir de uma frase, de uma palavra, de um livro, de um gesto, de uma imagem, ou seja, qualquer matéria que possa entrar numa relação de conversação ou diálogo entre sujeitos, provocando respostas, isto é, outros enunciados. No entanto, o material linguístico (orações, frases e palavras)
[...] pode repetir-se um número ilimitado de vezes em forma absolutamente idêntica, mas como enunciado (ou parte do enunciado) nenhuma oração, mesmo a de uma só palavra, jamais pode repetir-se: é sempre um novo enunciado (ainda que seja uma citação) (BAKHTIN, 2011, p. 313).

Deste modo, uma mesma palavra pode ter diferentes sentidos, a exemplo da palavra violência. Mas o sentido só poder ser analisado quando a palavra se torna um enunciado concreto, ou seja, uma resposta a outros enunciados, com autoria e destinatário (mesmo que presumido). O material linguístico é, nestes termos, o aparato técnico para a realização dos sentidos em um enunciado (BAKHTIN; VOLOCHÍNOV, 2010).

Se por um lado, palavras, gestos e até mesmo o silêncio se reiteram, o enunciado, por outro, é um acontecimento único e irrepetível. Ele é ao mesmo tempo produto e processo de um acontecimento. Deste modo, um enunciado está sempre no meio de uma rede de comunicação discursiva. Ele se conecta e responde aos enunciados que o precederam e, ao mesmo tempo, lança as possibilidades de contra-palavras, incita novas respostas e permanece como mais uma voz no plano dialógico da existência. Neste sentido, "não existe a primeira nem a última palavra, e não há limites para o contexto dialógico (este se estende ao passado sem limites e ao futuro sem limites)" (BAKHTIN, 2011, p. 410).

As condições que envolvem a produção de um enunciado são: a existência de um autor, de um interlocutor/destinatário conhecido ou não; a escolha de um gênero do discurso, que é uma forma relativamente estável de enunciado; o tema do enunciado, que é o seu sentido; as escolhas gramaticais e lexicais, que são os seus significados; e os presumidos encar- 
nados em determinados coletivos e comunidades (BAKHTIN, 2011). Um enunciado se define então pelos elementos de sua composição, que também estão relacionados a uma rede de outros enunciados a qual ele se vincula, como resposta e, ao mesmo tempo, como um novo endereçamento.

Entendemos que há em um enunciado verbal ou escrito múltiplas vozes com ideias-força ${ }^{3}$ que se reúnem e que fazem funcionar diferentes linguagens: econômicas, jurídicas, estatísticas, morais, entre outras. Estas linguagens, vozes e ideias-força compõem os enunciados em um dispositivo e, dar visibilidade e audibilidade a estes elementos é um dos principais trabalhos de uma perspectiva dialógica de análise. Tal análise tem como ponto de vista a refração das ideias-força sociais, políticas e culturais (BAKHTIN, 2010). Isso porque, as vozes que compõem um enunciado não são equipolentes, pois se objetivam em meio a relações de poder aonde exercem forças desiguais. As ideias-força nestas relações expressam e produzem modos de pensar, sentir e agir e, por consequência, colocam em cena as tensões presentes em cada enunciado.

As ideias-força podem se objetivar nas relações e nos enunciados de modo forte, fraco ou ainda latente, isto é, como uma possibilidade no horizonte da arena dialógica da existência. Assim, uma ideia-força ganha sentido na medida em que podemos analisar o contexto no qual o enunciado foi produzido e como ela se conecta ao grande diálogo de uma época, de uma cultura, de uma área de conhecimento, e

\footnotetext{
${ }^{3}$ O termo ideia-força é utilizado por Bakhtin (2010) no livro Problemas da Poética de Dostoievski, quando ele analisa a forma como Dostoievski recolhia da realidade as diferentes vozes e suas relações para compor a sua poética. Dostoievski, segundo Bakhtin (2010), auscultava de forma genial o grande diálogo de sua época; ele reconhecia ideias-forças fortes e fracas, do passado e do futuro, as ideias dominantes e também aquelas ainda latentes.
}

ainda, como ela contribui para a configuração de determinadas linguagens no campo das relações sociais, políticas, éticas, educacionais. Podemos dizer que a noção de ideia-força se aproxima também da noção de sentido de um enunciado, no entanto, ela assume o axioma de que a instituição de um sentido está sempre envolvida em uma arena de valores e de poderes que ganham vida no diálogo.

Cabe esclarecer que não nos interessava no trabalho de análise dos enunciados a autoria individual destes, mas as relações dialógicas que os compõem, isto é, o encontro das diferentes vozes em cada enunciado singular. Tratamos a questão da autoria desde a perspectiva de que todo enunciado se constitui de palavras alheias tornadas próprias e, neste sentido, nosso foco esteve na posição axiológica ocupada pelos sujeitos da enunciação e não em quem a realizou. Todo enunciado está carregado de um conteúdo vivencial singular e coletivo que demarca lugares de enunciação. Deste modo, em nossa pesquisa, tomamos a palavra violência como um enunciado, já que a partir dela podemos traçar inúmeras vozes e ideias-força e também criar novos sentidos, enunciando-a desde perspectivas de definição múltiplas.

Entendemos que o lugar de um pesquisador, ao entrar na rede de comunicação na qual ele se conecta, é de participação no diálogo com os enunciados e com os outros. O pesquisador é um terceiro ou quarto incluído no diálogo (BAKHTIN, 2011). É preciso, portanto, não renunciar, coincidir ou absorver a voz do outro, mas criar um campo possível, um entre lugar onde o pensamento e os afetos possam coexistir e ganhar passagem. É também neste entre que o pesquisador se expõe, pergunta, responde, assina o seu texto e assume uma posição de responsabilidade e responsivida- 
de pelo que produz (GROFF; MAHEIRIE; ZANELLA, 2010).

Uma pesquisa, com estes contornos epistemológicos, agrega, a nosso ver, um posicionamento ao mesmo tempo ético, estético e político:

Ético, no que se refere ao desejo de diferir e acolher a diferenciação constante; estético, no que se refere a tornar a existência e as práticas nas quais se produzem como matéria de criação e outramento; político, porque requer a problematização e a desnaturalização constante dos intoleráveis que atravessam a nossa existência e nos servem como indicadores de nossas ações em relação a nós mesmos e aos outros (NEVES, 2009, p. 209-210).

Estas dimensões podem afetar os significados fossilizados e colonizados do saber psicológico sobre o outro (GROFF; MAHEIRIE; ZANELLA, 2010), e podem nos comprometer, enquanto pesquisadores, com um modo de produção de conhecimento que não toma a vida como objeto, que não toma o outro como seu território; que força a olhar para o olhar que olha; que interroga as aderências às normas e aos discursos da normalidade; que interrompe palavras acostumadas; que mantém viva a pergunta pelo que um corpo pode, e menos pelo que ele é ou deve ser.

Um modo de pesquisar que tem no gesto exotópico a saída de uma autorreferência, a sua ancoragem, a sua possibilidade de dar um acabamento implicado, responsável pela produção discursiva que o estudo engendra. Isso porque, esta saída de si na produção de conhecimentos em Ciências Humanas tem a ver com a abertura de um espaço-tempo possível entre eu e o outro, entre o texto do pesquisador e o texto dos sujeitos da pesquisa, para que este outro não se torne um objeto reificado na produção do pesquisador (BAKHTIN, 2011). É deste modo que podemos criar um trabalho de análise não monológico, desancorado das metanarrativas que buscam sempre instituir uma verdade para aquilo que é por condição múltipla e incapturável, a saber, os corpos e seus afetos.

Com estas proposições teórico-metodológicas, apresentamos, desde o pensamento do Círculo de Bakhtin, a condição dialógica de todo e qualquer enunciado, pois em cada discurso verbal, em cada texto escrito, em cada imagem, há vozes em relação. O que a análise dialógica coloca em evidência são as vozes que estão em diálogo em um dispositivo. O que a dialogia como perspectiva de trabalho pode dar a ver é o lugar de enunciação, a textualidade dos afetos, as vozes e forças que o compõe. Mas é preciso um olhar atencioso do pesquisador para as tensões presentes em um mesmo enunciado, como também para a disputa entre posicionamentos e seus efeitos na rede discursiva. Além disso, é preciso ter clareza de que não é possível trabalhar com a totalidade da rede infinita na qual a pesquisa se situa. É necessário fazer escolhas, recortar o plano de imanência, criando assim o plano da pesquisa.

\section{Um Recorte Necessário}

Ao nos relacionarmos com os materiais do curso e com o ambiente virtual enfrentamos a difícil tarefa de eleger dentre tudo o que nos estava acessível, tanto impresso como de modo virtual, quais seriam nossos materiais de estudo, isto é, qual seria o recorte para realização da análise dialógica. A partir da pergunta pelo como a violência foi enunciada na experiência do curso de especialização, dos elementos que envolvem a objetivação de um enunciado e da dialogia como uma perspectiva de trabalho in- 
vestigativo, reconhecemos a necessidade de criar alguns critérios de escolha dos materiais.

Escolhemos recortar a análise dos enunciados produzidos somente pelos estudantes vinculados a um polo regional do curso. A escolha de apenas um polo aconteceu devido à necessidade de trabalharmos com uma produção textual adequada a nossa perspectiva de análise, tendo em vista a enorme quantidade de informações no âmbito geral da formação. Com a delimitação do polo houve um recorte do espaço virtual a ser analisado, ou seja, os registros vinculados a um determinado grupo de cursistas no ambiente virtual do curso de especialização. Como nosso interesse era olhar para o modo como a violência foi enunciada considerando o processo da formação, focamos nossa análise em temporalidades distintas desta trajetória e nos registros textuais tanto do curso como dos cursistas ${ }^{4}$.

Em relação aos registros textuais do curso, priorizamos a análise do Projeto Político Pedagógico e os materiais didáticos impressos. Quanto aos registros dos cursistas, elegemos aqueles produzidos no início e no final da formação e com os quais os cursistas não estivessem necessariamente preocupados em criar respostas endereçadas aos professores e/ou tutores por conta de uma avaliação pressuposta por estes. No caso das atividades em que ocorreram avaliações, optamos por aquelas realizadas em grupo. Deste modo, nossa leitura e análise estiveram focadas, no caso dos estudantes, em um questionário respondido no ato da matrícula, nos registros destes em alguns fóruns e nos Projetos de Intervenção Educacionais (PIE's) elaborados em grupos.

\footnotetext{
${ }^{4}$ Projeto de Pesquisa Aprovado pelo Comitê de Ética da Universidade Federal de Santa Catarina (UFSC), sob o Parecer no 334.350 em 08 de julho de 2013.
}

O questionário foi produzido pela coordenação do curso e constava de: I - Identificação e aspectos socioeconômicos e Formação Acadêmica; II - Experiências com novas tecnologias; III - Inventário Conceitual. Responderam ao questionário um total de 490 cursistas. No caso do polo escolhido, 37 dos 40 matriculados responderam o questionário, sendo os dados destes 37 estudantes especialmente trabalhados por nós na produção de informações para a pesquisa.

O fórum, em um ambiente virtual, se constitui em uma ferramenta assíncrona que cria espaços de discussão por meio da troca de mensagens, geralmente em forma textual, encadeadas e visíveis a todos que dele participam (LAPA; BELLONI, 2010). Nos fóruns, é possível criar tópicos de discussão sobre um mesmo tema, registar ideias, impressões, fazer perguntas, enfim, é um espaço mais aberto de diálogo onde cada um e cada uma pode se expressar desde a sua temporalidade. Como a especialização aconteceu no período de maio de 2010 a agosto de 2011, também houve na pesquisa um olhar que intentou capturar o processo da formação e, por isso, analisamos fóruns do início e do final do curso.

Os fóruns que entraram no recorte da pesquisa foram o Fórum de Apresentação, Fórum da Introdução à Educação a Distância e Fórum do Módulo III. O Fórum de Apresentação foi criado logo no início do curso para que os cursistas pudessem se apresentar aos colegas e aos professores e, ainda, para que pudessem interagir e com isso iniciar o contato com a plataforma virtual. Este fórum ficou aberto durante aproximadamente um mês, pois o curso também recebeu alunos novos devido às vagas remanescentes e que posteriormente puderam utilizar esta ferramenta.

O Fórum da Introdução à Educação a Distância foi criado com o objetivo de estabelecer 
a comunicação entre os participantes do curso. Nele encontramos a criação de tópicos por parte dos cursistas onde estes iniciavam diálogos sobre assuntos variados e de forma espontânea. Já o Fórum do Módulo III se constituiu em uma atividade proposta pelo professor do Módulo, onde os cursistas tinham que propor intervenções em situações de preconceito na escola e dialogar com os colegas sobre as propostas de intervenção elaboradas. Assim, cada estudante criou um tópico de discussão no qual expôs a sua proposta de intervenção e outras reflexões.

Os Projetos de Intervenção Educacionais analisados integraram as atividades dos três Módulos de conteúdos básicos previstos na matriz curricular da especialização. Instrumentalizar os cursistas para a elaboração de Projetos de Intervenção foi um dos principais objetivos do curso, por isso optamos por analisar a versão final dos quatro PIE's vinculados ao polo escolhido e, apesar de terem sido avaliados, se configuraram em produções coletivas.

Com relação aos materiais do curso, analisamos os seguintes: Projeto Político Pedagógico, livro do Projeto de Intervenção Educacional; livro da Introdução à Educação a Distância e; os três livros de conteúdos teóricos: Módulo I - Gestão do Cuidado e Educação Biocêntrica; Módulo II - Violências, Rede de Proteção e Sistema de Garantia de Direitos; Módulo III Educação, escola e violências.

\section{Leitura e Escrita: ferramentas metodológicas}

A leitura destes materiais foi nossa principal ferramenta metodológica. Ler exige do pesquisador uma disposição para olhar o olhar do outro, como também para olhar o olhar que olha.
Isto é, estar atento aos efeitos do discurso do outro em nós, como ele nos afeta, o que ele nos faz pensar, quais as possibilidades de (de) composição com os enunciados de outrem. A leitura, neste sentido, pode se constituir em um acontecimento da alteridade, "[...] cujas consequências diferem de leitura para leitura, de leitor para leitor" (SKLIAR, 2014, p. 85). A leitura também possui motivações e temporalidades múltiplas conforme as características do material a ser lido. Não lemos um romance da mesma forma que lemos o jornal, como não lemos uma poesia da mesma forma que lemos uma imagem, não lemos um material científico da mesma forma que uma charge. Mas, apesar disso, todos estes textos podem ser objeto de uma leitura acadêmico-científica.

A leitura que tem como finalidade a produção de conhecimentos não pode se eximir de uma responsabilidade ética no trato com o material em análise. Material este que é sempre um discurso citado, discurso de outrem e, por isso, não pode ser coisificado. Além disso, a leitura acadêmico-científica pressupõe também a escrita, ou seja, uma intervenção, ato pelo qual o pesquisador precisa se responsabilizar. Por isso, entendemos com Zanella (2013) que mesmo a análise de documentos/textos,

[...] considerados 'não reagentes' porque não respondem ao pesquisador, podem ser considerados como intervenção na medida em que produzem conhecimentos que modificam ou podem vir a modificar o modo como determinada situação é lida/percebida/enunciada. Seus resultados, uma vez tornados públicos, apresentam-se como dispositivos a deflagrar diálogos e intervenções outras, a modificar as relações que as pessoas com esta estabelecem. Resultados, portanto, não somente explicam situações e contextos, mas em sendo reconhecidos como discursos de verdade, os fundam (ZANELLA, 2013, p. 161-162). 
Tal responsabilidade passa então pelo nosso compromisso tanto com a leitura quanto com a escrita, já que esta composição pode exercer, no campo da produção de conhecimentos, efeitos significativos na vida de destinatários pressupostos ou não à pesquisa. Assim, se a leitura pode ser um acontecimento da alteridade, ela também pode fazer com que o enunciado do outro permaneça sendo outro no ato da escrita acadêmica - um desafio à perspectiva dialógica de trabalho. E a linguagem acadêmica - como um gênero de discurso relativamente estável no campo das ciências - pode, a partir de uma leitura alterizada e de uma escrita dialógica, possibilitar a criação de um espaço vivo entre o pesquisador e os sujeitos da pesquisa, um espaço intenso e povoado pela diferença e por vozes múltiplas. Uma leitura e uma escrita, neste sentido, contrárias à monologia que reifica a vida e o mundo (BAKHTIN, 2011), abertas à polissemia, à multiplicidade dos corpos e ao que os encontros entre estes são capazes de criar e inventar no plano de uma pesquisa.

Portanto, se a leitura foi nossa principal ferramenta metodológica, a dialogia foi a estratégia utilizada para a escuta das vozes, bem como o princípio para que estas vozes se mantivessem vivas e em constante luta no processo de análise, diálogo e escrita do texto da pesquisa. Uma estratégia de difícil execução, pois a perspectiva de trabalho dialógica faz com que nossa relação com o material de estudo transborde para territórios sem limites. As possibilidades de conexão entre enunciados, de ontem e de hoje, vão ganhando cada vez mais força e espaço na medida em que vamos auscultando uma multiplicidade de vozes. Por vezes, um mesmo enunciado carrega tantas ideias e forças que seria possível nos determos apenas nele, na análise de sua dialogia. Porém, a proposta deste estudo era também a de analisar as relações dialógicas entre enunciados e nos lançamos neste desafio.

Primeiramente sistematizamos as informações produzidas com o questionário em gráficos. Depois retiramos todo o conteúdo dos fóruns do ambiente virtual e criamos arquivos em editor de texto para que fosse possível sua leitura de um modo mais unidimensional e para que tivéssemos condições de destacar as vozes e as ideias fortes, fracas e ainda latentes nos enunciados, bem como seus entrecruzamentos. Dividimos os textos de acordo com os três fóruns selecionados. Em cada texto fomos destacando as vozes que íamos escutando, tais como: texto 1) as expectativas dos cursistas com a especialização, a dificuldade para lidar com a temática da violência na escola, a vontade de trocar experiências; texto 2) família, valores, mídia, tipos de violência na escola; texto 3) o lugar da diferença e da diversidade, inclusão, tipos de intervenção; entre outras.

A partir destas vozes, fomos criando perguntas e afirmações que as conectavam a ideias-força possíveis à experiência com esta pesquisa. O pesquisador, sua trajetória de vida, sua condição social, política e cultural, os interlocutores que lhe ajudam a pensar, são os filtros que possibilitam que determinadas análises aconteçam, em detrimento de outras. O pesquisador como aquele que está entre uma rede discursiva, colhe desta rede percepções, sentimentos e pensamentos que lhe foram acessíveis antes e durante o processo da investigação, para compor outros e novos enunciados com os enunciados dos outros.

Assim, a leitura inicial se concentrou nos registros dos fóruns, mas não de modo sequencial. Iniciamos a leitura dos textos do Fórum de Apresentação e, a partir do que encontramos nele, percebemos a possibilidade de articulá-lo com uma das perguntas do questionário e com 
o Projeto Político Pedagógico do curso. Deste modo, colocamos em relação, tensão e composição os enunciados dos cursistas com os enunciados do curso e, ainda, a outras vozes com as quais estes se conectavam, tais como legislações e documentos vinculados ao Ministério da Educação. A partir disso criamos um estudo introdutório que articulou as expectativas dos estudantes e os anseios da especialização.

Agregamos parte do texto 1 e do questionário à leitura e análise do texto do Fórum da Introdução a EaD, pois a partir destes materiais é que identificamos a possibilidade de olharmos para o modo como os cursistas enunciaram a violência no início da formação. Trabalhamos então para colocar em diálogo os enunciados dos cursistas com os materiais didáticos, criando o que se configurou no estudo sobre como a violência foi enunciada na experiência do curso de especialização.

Depois disso, pensamos em articular a leitura do texto vinculado ao Fórum do Módulo III com os quatro Projetos de Intervenção Educacionais, pois tínhamos o objetivo de olhar para os efeitos do curso no processo da formação, se e como os enunciados dos cursistas foram se modificando nesta trajetória. No entanto, ao finalizar a leitura do texto 3, percebemos que este merecia uma análise específica por conta da quantidade e qualidade das informações ali presentes. Nele encontramos não só as permanências e as mudanças no processo da formação, mas o modo pelo qual determinados discursos trazidos pelos materiais do curso foram ganhando espaço no modo de enunciar dos cursistas. Além disso, este fórum nos fez refletir sobre o lugar da diferença, da diversidade e da alteridade na produção de discursos na experiência desta formação.

Por fim, realizamos a leitura dos Projetos de Intervenção Educacionais elaborados pelo polo selecionado e que se revelaram como um produto final da especialização. Nos PIE's observamos, de certo modo, a experiência coletiva do curso se objetivar, pois encontramos a concretização das expectativas e anseios pela intervenção, os efeitos da metodologia proposta para a elaboração dos Projetos, os modos de enunciar a violência atravessada pelas vozes do curso e entrelaçadas a outras.

Criamos nesta direção um modo de pesquisar no próprio processo da pesquisa, já que antes disso, não tínhamos um método, mas uma perspectiva de trabalho que posicionou $e$ direcionou nossas leituras, análises e escritas. Um modo de pesquisar (e)feito de um processo de experimentação, de pensar e escrever sobre o que nos passou no ato da leitura, das anotações, das perguntas, afirmações e desconhecimentos, e que deu ritmo a um modo de produção de conhecimento que articula em uma só pauta teoria e método. Neste ritmo é que vamos constituindo-nos como pesquisadores e, ao mesmo tempo, criando e reinventando nossa pesquisa (GROFF; MAHEIRIE; ZANELLA, 2010).

\section{Considerações finais}

O trabalho de análise foi um exercício de criação objetivado durante a experiência das leituras e escritas. Neste sentido, não há uma imagem de método a ser reproduzida quando se parte da dialogia como perspectiva de trabalho. Cada pesquisador vai precisar criar, a seu modo, estratégias tanto de leitura dos materiais como de escrita do trabalho, pois vai depender do seu lugar na pesquisa, da dedicação, do tempo e da disponibilidade para diferir de suas convicções iniciais, para dar voz ao outro e com ela tensionar outras vozes, para problematizar o próprio olhar e, em meio a tudo 
isso, pensar também nos leitores e interlocutores presumidos ou não. Visualizar possíveis leitores é importante tanto no sentido de detaIhar e esclarecer aspectos da escrita, conexões e ideias que a princípio pareciam óbvias, como para criar a possibilidade de encontro com aqueles com quem se quer, em outra temporalidade que não a da escrita, dialogar.

Entre os desafios e as possibilidades de uma análise dialógica, gostaríamos de partiIhar algumas observações identificadas durante o processo da pesquisa, as quais podem ser vistas como pistas que poderão auxiliar ou minimizar os entraves de uma investigação dialógica em espaço virtual. Em primeiro lugar, vale destacar que a preparação do material a ser analisado é fundamental. No nosso caso foi imprescindível trabalhar com os textos impressos, uma vez que a leitura e conexão entre textos no computador nos mostrava um limite visual, ou seja, não havia como visualizá-los todos de uma vez. Com os textos impressos, podemos manejá-los em uma superfície, aproximando-os, fazendo composições e exclusões. É como se um mapa de textos, palavras e vozes ganhasse vida na medida em que o pesquisador vai dando audibilidade e visibilidade às múltiplas vozes presentes, ausentes e presumidas.

Em segundo lugar, a leitura é a principal ferramenta em uma análise que se quer dialógica. Para tanto, ler, reler e reler uma vez mais os materiais da pesquisa, bem como os escritos teóricos, nunca é demais. A cada leitura, outros sentidos vão se fazendo visíveis e possíveis ao pesquisador. O processo da leitura é ao mesmo tempo um trabalho de análise, portanto, as apropriações teóricas, o conhecimento sobre o campo da pesquisa, sobre os sujeitos e as vozes dos enunciados emergem ao pesquisador e vão sendo conectados entre leituras e escritas. Esta pode ser uma experiência desconfortável, pois traz com ela a sensação de que não vamos conseguir objetivar na escrita tudo o que pensamos no momento da leitura e que o tempo para isso também não será suficiente. Por isso, a dica é para que se tenha sempre um caderno de anotações onde perguntas, afirmações, articulações teóricas, etc., possam ser registradas e depois retomadas na hora da escrita do trabalho.

Em terceiro lugar, neste processo, não há necessariamente a criação de categorias de análise, pois o objetivo de uma análise dialógica é trabalhar com as vozes que constituem um enunciado e, também, com as quais ele se relaciona em um contexto extraverbal mais amplo. O trabalho a ser realizado terá de ser pautado nos objetivos do pesquisador, naquilo que mais o afetou no momento da leitura e nos limites que ele terá que impor à análise, pois esta é uma forma de trabalho que pode se estender sem limites. No caso de nossa investigação criamos estudos ou capítulos a partir do cruzamento do próprio material de análise, ou seja, os materiais da pesquisa é que foram sinalizando as possiblidades dos estudos e a sensibilidade do pesquisador com sua problemática de investigação é que vai direcionando e criando um novo texto, o texto da pesquisa.

Por último, mas poderia ser por primeiro, o principal gesto de uma análise dialógica passa pela pergunta: como um determinado enunciado foi possível? A partir disso, podemos lançar olhares para as condições históricas de possibilidade de existência de um enunciado, para as vozes sociais, políticas, culturais, cotidianas e da ciência, para os lugares de enunciação, para as relações de poder e, também, lançar olhares que se voltam àquele que olha. 


\section{Referências}

BAKHTIN, M. Problemas da Poética de Dostoiévski. 5. ed. Rio de Janeiro: Forense Universitária, 2010.

BAKHTIN, M. Estética da Criação Verbal. 6. ed. São Paulo: Martins Fontes, 2011.

BAKHTIN, M.; VOLOCHINOV, V. Discurso na Vida e Discurso na Arte. Tradução de Carlos Alberto Faraco e Cristovão Tezza. New York: Academic Press, 1976.

BAKHTIN, M.; VOLOCHÍNOV, V. Marxismo e Filosofia da Linguagem. 14. ed. São Paulo: Hucitec, 2010.

DELEUZE, G. Conversações. 2. ed. São Paulo: Ed. 34, 2010.

FOUCAULT, M. Sobre a História da Sexualidade. In: FOUCAULT, M. Microfísica do Poder. Rio de Janeiro: Graal, 1979. P. 243-276.

FOUCAULT, M. Vigiar e Punir: nascimento da prisão. 36. ed. Petrópolis: Vozes, 2009.

FOUCAULT, M. História da Sexualidade I: a vontade de saber. 22. ed. Rio de Janeiro: Ed. Graal, 2012.

GROFF, A.R. Relatório do Curso de Especialização: a gestão do cuidado para uma escola que protege: Convênio UFSC/MEC/SECADI: 2009 a 2011. Supervisão: Ana Maria Borges de Souza, Patrícia de Moraes Lima. Florianópolis: UFSC, [2011?]. Disponível em: <http://nuvic.paginas.ufsc.br/ files/2015/03/Relatorio-Final-EQP_MEC_SECADI.pdf> Acesso em: 20 maio 2015.

GROFF, A.R. Entre Vozes e Linguagens Para Enunciar a Violência: análise dialógica de uma experiência de formação continuada para professores/as. 2015. 270 f. Tese (Doutorado em Psicologia) - Programa de Pós-Graduação em Psicologia, Universidade Federal de Santa Catarina, 2015, Florianópolis, BR-SC.

GROFF, A.R.; MAHEIRIE, K.; ZANELLA, A.V. Constituição do(a) Pesquisador(a) em Ciências Humanas. Arquivos Brasileiros de Psicologia, Rio de Janeiro, v. 62, n. 1, p. 97-103, 2010.

LAPA, A.B.; BELLONI, M.L. Introdução à Educação a Distância. Florianópolis: UFSC/CED/NUP, 2010.

NEVES, C.A. Gilles Deleuze e Política: interferências nos modos de se estar nos verbos da vida. In: TEDESCO, S.; NASCIMENTO, M.L. Ética e Subjetividade: novos impasses no contemporâneo. Porto Alegre: Sulina, 2009. P. 191-212. 
REATEGUI, E. et al. Editorial. Informática na Educação: teoria e prática, Porto Alegre, v. 14, n. 2, p. 9-10, jul./dez. 2011.

SANTOS, J. de D. dos. Formação Continuada: cartas de alforria \& controles reguladores. 2006. 170 f. Tese (Doutorado em Educação) - Programa de Pós-Graduação em Educação, Faculdade de Educação, Universidade Federal do Rio Grande do Sul, 2006, Porto Alegre, BR-RS.

SKLIAR, C. Desobedecer a Linguagem: educar. 1. ed. Belo Horizonte: Autêntica, 2014.

SKLIAR, C.; TÉLLEZ, M. Conmover la educación: ensayos para una pedagogia de la diferencia. Buenos Aires: Centro de Publicaciones Educativas y Material Didáctico, 2008.

ZANelLA, A.V. Perguntar, Registrar, Escrever: inquietações metodológicas. Porto Alegre: Sulina; Ed. da UFRGS, 2013.

Submetido para avaliação em 04 de agosto de 2015.

Aprovado para publicação em 24 de setembro de 2015.

Apoliana Regina Groff - Universidade Federal de Santa Catarina, Florianópolis, BR-SC. E-mail: poligroff@gmail.com Kátia Maheirie - Universidade Federal de Santa Catarina, Florianópolis, BR-SC. E-mail: maheirie@gmail.com 